\title{
16. GEOPHYSICAL SURVEYS AT SITES 120, 121, AND 132 OF THE DEEP SEA DRILLING PROJECT
}

\author{
Eric Christofferson and Martin R. Fisk, Graduate School of Oceanography, \\ University of Rhode Island, Kingston, Rhode Island
}

\section{INTRODUCTION}

Three sites of Leg 13 of the Deep Sea Drilling Project were surveyed in the fall of 1970 by the R/V Trident of the University of Rhode Island (Figure 1). Site 132 in the Tyrrhenian Basin, Site 121 in the western Alboran Basin, and Site 120 on Gorringe Bank were all profiled subsequent to the drilling activity during Cruise $\operatorname{Tr}(88)$, from Naples, Italy to Punta Delgada in the Azores.

Underway geophysical investigations included continuous $12 \mathrm{kHz}$ precision echo sounding (PESR), measurements of the total magnetic field intensity (Varian proton precision magnetometer), and continuous seismic reflection profiling.

The profiling system consisted of a Bolt pneumatic sound source with 20 and 10 cubic inch chambers and operating at $2000 \mathrm{psi}$, and a Woods-Hole-OceanographicInstitution-designed, 100 foot, 200 element (Aquadyne type AQ-1) streaming hydrophone. The hydrophone contained a $40 \mathrm{~dB}$ preamplifier. The unfiltered signal was recorded on magnetic tape and the filtered signal was recorded on a Raytheon Precision Fathometer Recorder. The filter settings were usually $37 \frac{1}{2}$ to $120 \mathrm{~Hz}$, and occasionally 75 to $120 \mathrm{~Hz}$. The ship's speed while profiling was 6 knots.

At Sites 120 and 121, heat flow stations were occupied, but the data will be reported elsewhere. Navigation control included both celestial fixes and those from the Navy Navigational Satellite System (NNSS) using a Magnavox $706 \mathrm{CA}$ receiver and data processor.

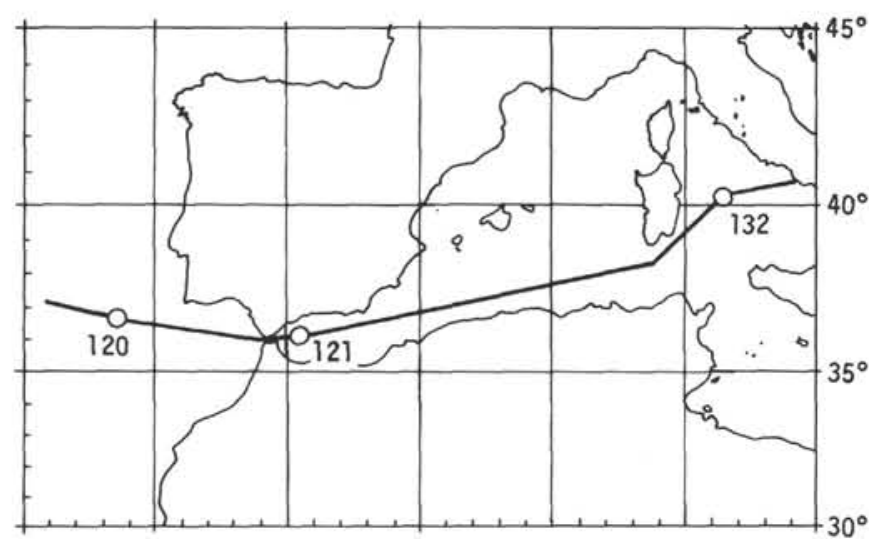

Figure 1. Track of $R / V$ Trident Cruise No. 88 showing the locations of the three site surveys.

\section{DISCUSSION}

\section{Site 120 - Gorringe Bank}

The reflection profiles across Site 120 are shown in Figure 2. Also shown are the bathymetric and magnetic profiles and the survey navigation. The ship's track initially crosses Gorringe Bank at $2320 \mathrm{~h}$ along the south shoulder of the Ormonde shoal where water depth is only 138 meters. Sediments are undetectable over much of the summit, but in some places (such as, $2355^{\mathrm{h}}$ ) pockets of sediment 0.1 second thick do occur. The shallower parts of the bank show the typical terrace erosion and deposition that is characteristic of the Pleistocene glacially-lowered sea level. On the lower flanks of Gorringe Bank, just a little to the north of the drill site, sediments are as much as 0.3 second thick, with sediments thickening to the west. It can be seen in the survey line from $0310^{\mathrm{h}}$ to $0510^{\mathrm{h}}$ that the north flank of Gorringe Bank has a uniform slope and that the sediments thin toward the top. The track segment from $0510^{\mathrm{h}}$ to $0610^{\mathrm{h}}$, along the crest of the bank where the water depth is 350 to 550 meters, shows pockets of sediment up to 0.4 second in thickness, whereas the shallow points have the least sediment.

\section{Site 121 - Western Alboran Basin}

The bathymetric and magnetic profiles in the vicinity of Site 121 are illustrated in Figure 3 along with the navigational plot. The reflection profile (Figure 4) from $0645^{\mathrm{h}}$ to $0908^{\mathrm{h}}$ shows a gradual decrease in depth northward toward Spain with several strongly reflecting horizons in the first 0.4 second below the water-sediment interface. There is a sharp dip in the 3rd reflecting layer just after $0700^{\mathrm{h}}$. Between $0645^{\mathrm{h}}$ and $0745^{\mathrm{h}}$ and below 0.4 second, two sloping reflecting horizons can be seen dipping to the south. Between $0745^{\mathrm{h}}$ and $0845^{\mathrm{h}}$, reflecting horizons below 0.4 second are still present but are parallel to the upper sediment reflectors. The profile segment from $0908^{\mathrm{h}}$ to $1010^{\mathrm{h}}$ also shows the strong conformable reflectors in the first 0.4 second and secondary reflectors as deep as 0.8 second. The line from $1010^{\mathrm{h}}$ to $1224^{\mathrm{h}}$ has all the same reflectors as the previous two lines, and all slope toward the east, the deeper reflectors having a greater slope than the shallower ones. The reflectors become level at $1045^{\mathrm{h}}$ and remain level until $1200^{\mathrm{h}}$ where they begin to slope to the west.

\section{Site 132 - Tyrrhenian Basin}

The bathymetric profile and navigation from the survey at Site 132 appear in Figure 5; no magnetic measurements were made. The reflection profile (Figure 6) has a scale change at $1828^{\mathrm{h}}$ from a two-second sweep presentation to a more condensed five-second sweep. The prominent subbottom reflector beneath the upper transparent sediment cover corresponds to the top of the evaporite rocks recovered from the drill hole. The evaporite series is apparently layered, as evidenced in the marked internal stratification along the track segment from $2100^{\mathrm{h}}$ to $0100^{\mathrm{h}}$. 


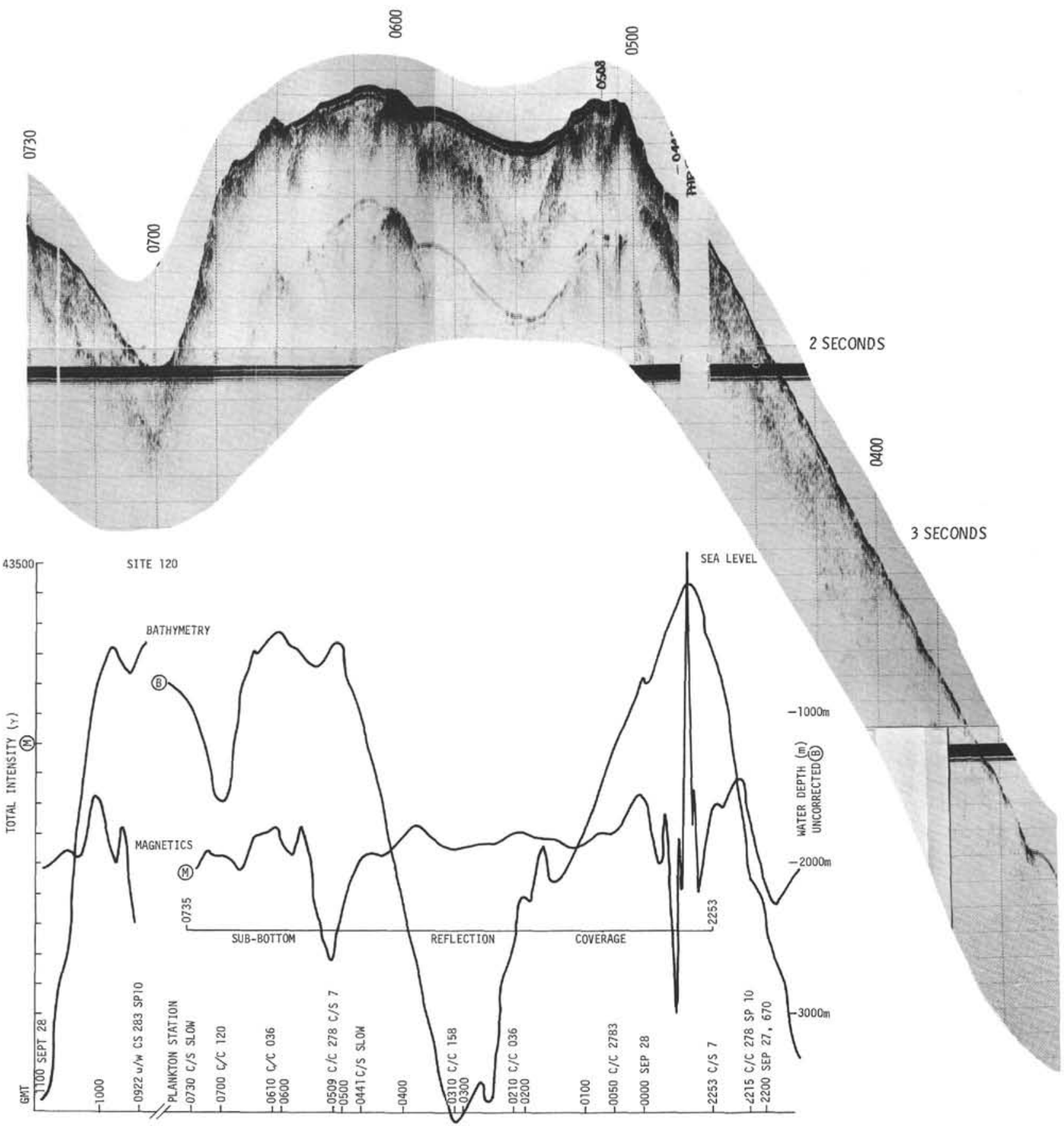

Figure 2. Bathymetric, magnetic and seismic reflection profiles of the Gorringe Bank (120) survey. In the navigation plot the triangles represent satellite fixes. 


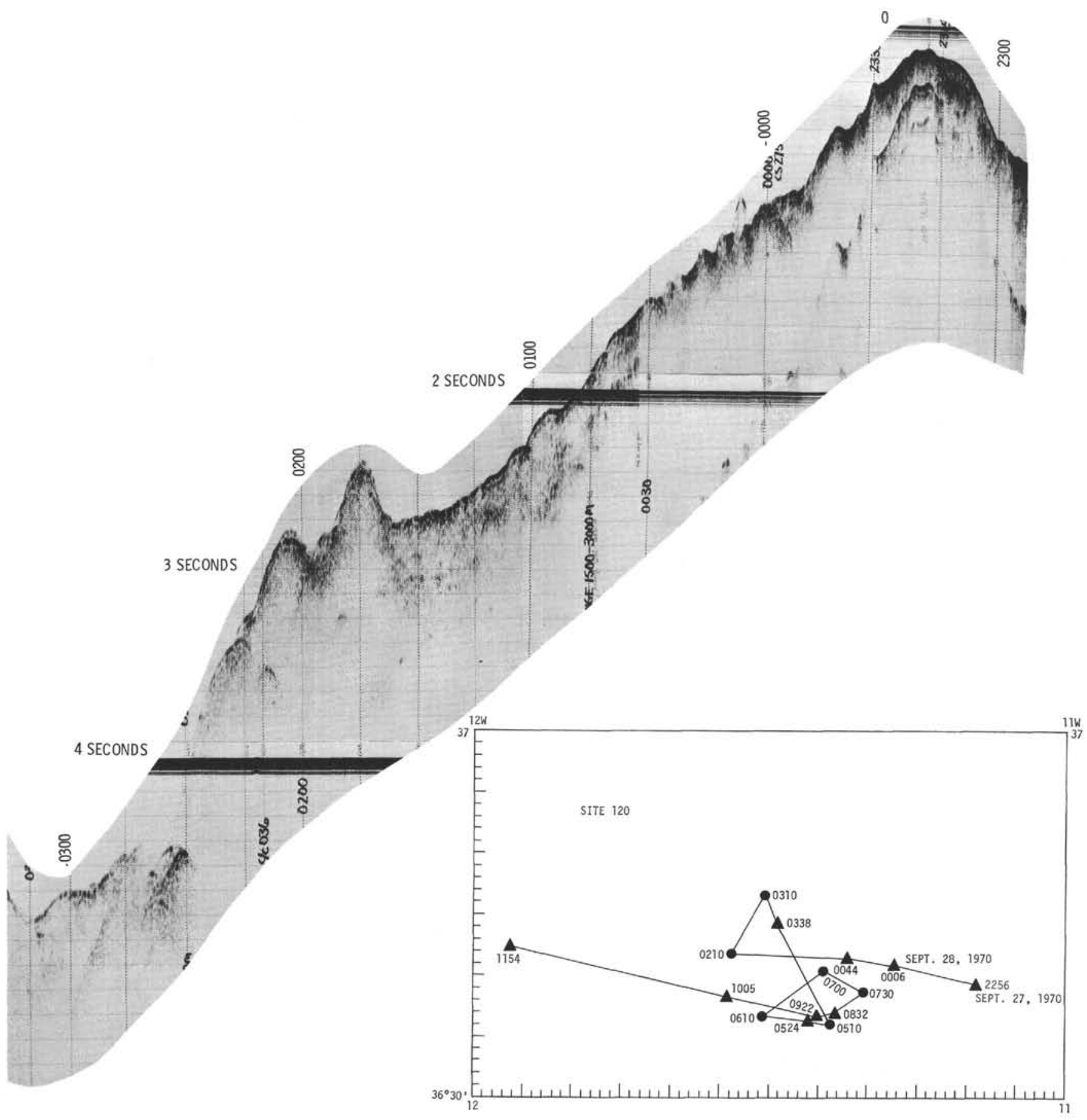

Figure 2. Continued . 


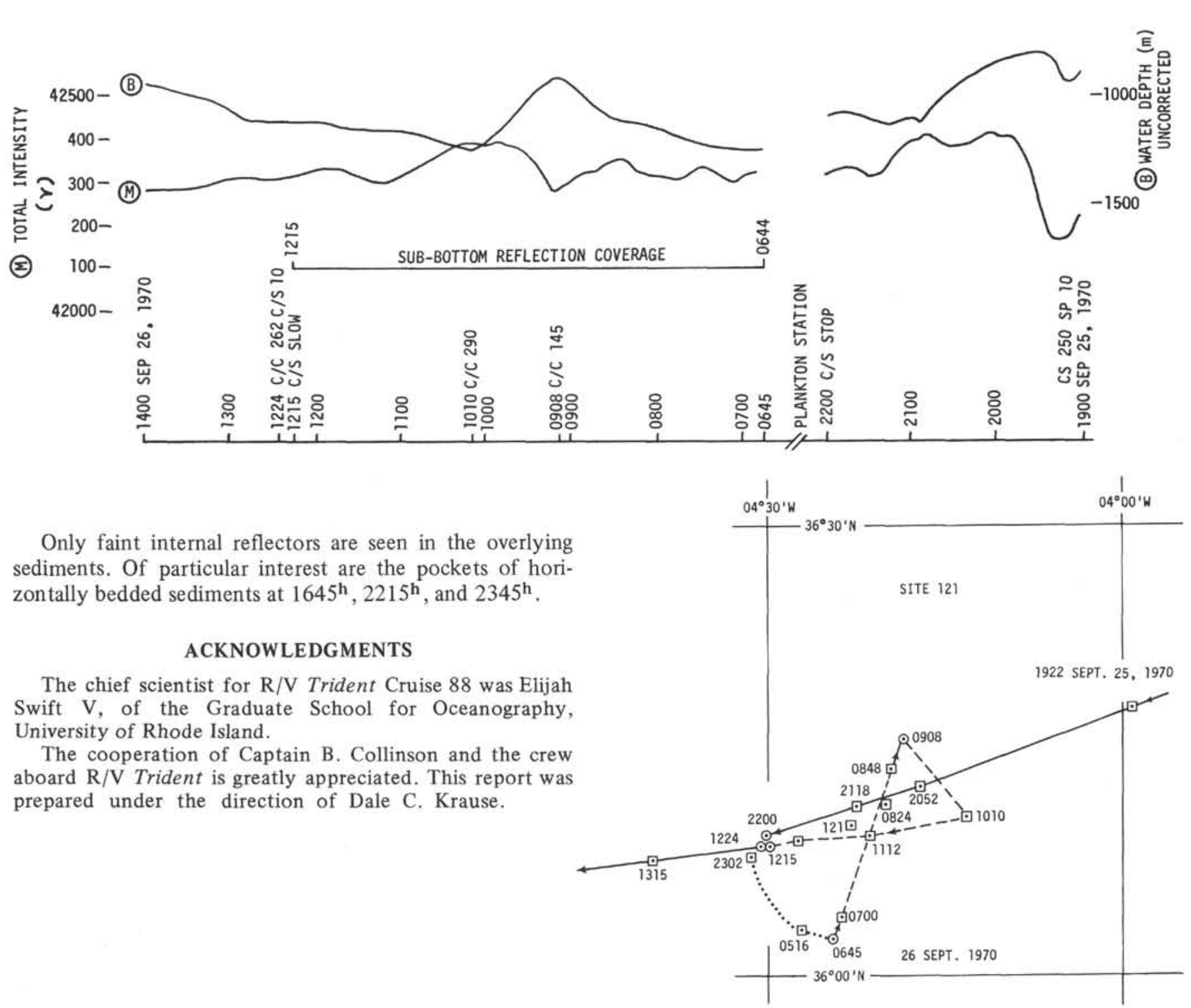

Figure 3. Bathymetric and magnetic profiles of the Alboran Basin (121) survey.

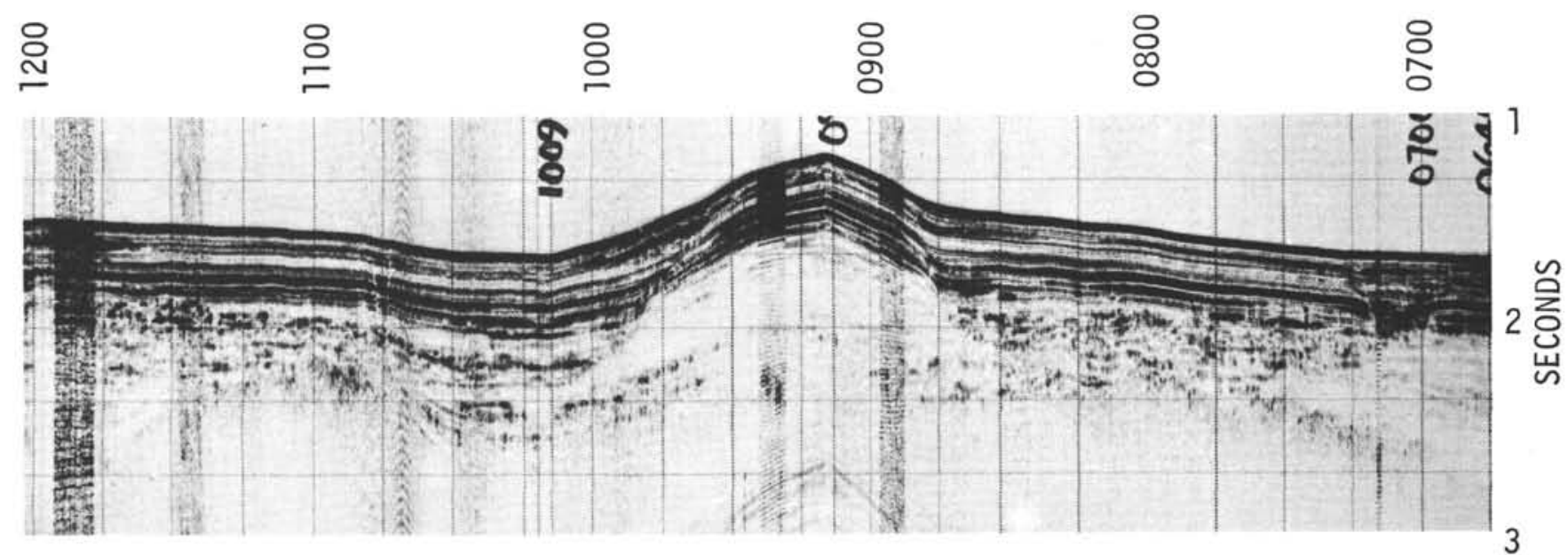

Frgure 4. Continuous seismic reflection profile in the vicinity of Site 121. Vertical scale is in seconds of two-way travel time. 


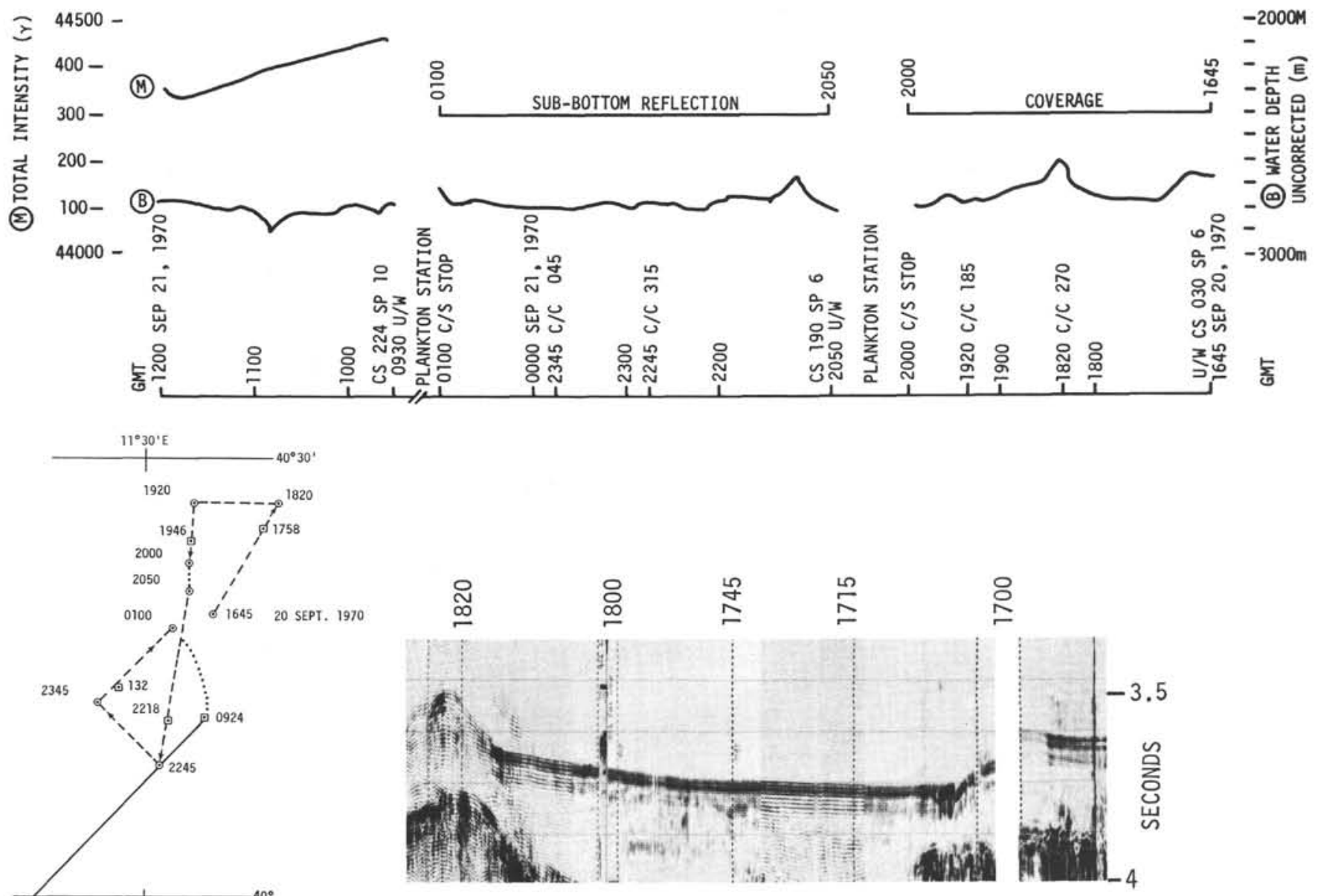

Figure 5. Bathymetric and magnetic profiles of the Tyrrhenian Basin (132) survey.
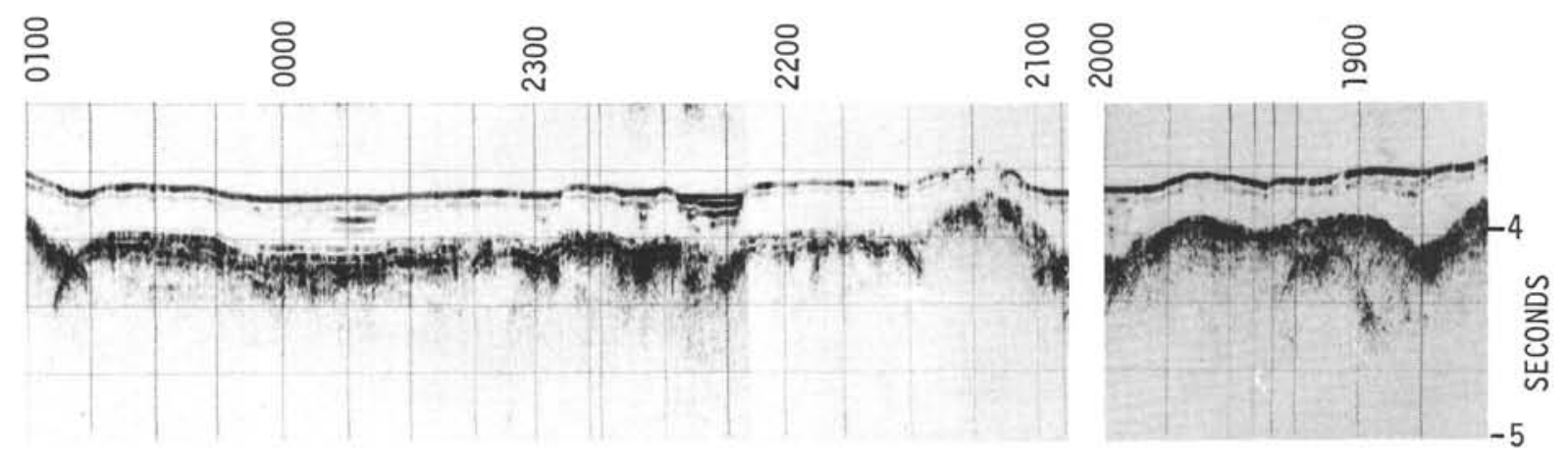

Figure 6. Continuous seismic reflection profile in the vicinity of Site 132. The strong sub-bottom reflector represents the Upper Miocene evaporite series. 